\title{
A New Acetylcholinesterase Inhibitor from Green Glycosylation of Trachyloban-19-oic Acid by Mucor plumbeus
}

\author{
GABRIEL F. DOS SANTOS AND JACQUELINE A. TAKAHASHI
}

\begin{abstract}
Departamento de Química, Instituto de Ciências Exatas, Universidade Federal de Minas Gerais, Av. Antonio Carlos, 6627, Pampulha, 31270-901 Belo Horizonte, MG, Brazil
\end{abstract}

Manuscript received on April 3, 2017; accepted for publication on June 15, 2017

\begin{abstract}
The in vitro metabolism of a widespread natural product, trachyloban-19-oic acid (1), by the fungal species Mucor plumbeus was studied in a sucrose-yeast liquid medium. Two products were isolated, and their structures were determined by spectroscopic means as $7 \beta$-hydroxytrachyloban-19-oic acid (5) and trachyloban-19-O- $\beta$ - $D$-glucopyranosyl ester (6). To the best of our knowledge, compound $\mathbf{6}$ is herein reported by the first time in the literature. These compounds were assayed for acetylcholinesterase inhibition along with some related compounds. Compound $\mathbf{6}$ showed the highest acetylcholinesterase inhibitory activity at $10000 \mu \mathrm{g} / \mathrm{mL}$ among the tested compounds, a result $(92.89 \%)$ comparable to the activity of the positive control, galanthamine (94.21\%). Therefore, biotransformation of the natural product 1 by $M$. plumbeus produced a novel compound with potential as a new lead to develop anti-Alzheimer medicines.
\end{abstract}

Key words: acetylcholinesterase inhibitors, biotransformation, green glycosylation, Mucor plumbeus, trachyloban-19-oic acid.

\section{INTRODUCTION}

Pharmaceutical interest on synthesis of new natural products derivatives has increased due to multiple bioactivities related to these compounds (Alvin et al. 2014). A modern synthetic strategy for producing new natural products consists on biotransformation, due to its capacity to introduce functional groups in different positions of carbon skeleton, thus improving pharmacological properties of target compounds (Yang et al. 2015). In fungi, there is a large variety of enzymes, which have been proved to be useful for biocatalytic processes, catalyzing

Correspondence to: Jacqueline Aparecida Takahashi

E-mail: jat@qui.ufmg.br many chemical reactions, including oxidations, hydroxylations, and reductions among others (Baydoun et al. 2016). Besides, this methodology presents regio- and stereo-selectivity due to the chiral nature of enzymes and can be accomplished at room temperature, under neutral aqueous conditions. Biotransformations carried out with whole cells have yet the advantages of no need of expensive cofactors. Therefore, enzymatic reactions conducted by fungi have been a promise for a greener organic chemistry, thus contributing to a growing advance in the development of new drugs from compounds of natural origin (Hollmann et al. 2011, Xu et al. 2016). 
Mucor species are known as an important bioresource, bearing rich enzyme systems and fast growth. Fungi from Mucor genus usually do not produce mycotoxins and are thermotolerant, making them one of the first choice species to be employed in biotechnological processes (Nunes et al. 2013, Silva et al. 2014). Mucor species are able to make chemical modifications in the skeleton of structurally diverse natural products such as terpenes (Chen et al. 2015), steroids (Donova and Egorova 2012), coumarins (Lv et al. 2012), among other (Silva et al. 2014).

Alzheimer's disease is a degenerative neurological disorder which has becoming a very concerning problem in contemporary world. Inhibition of acetylcholinesterase (AChE) enzyme by drugs as galanthamine is currently the most established approach to treat Alzheimer's disease (Najaf et al. 2017). Search for new acetylcholinesterase inhibitors, equally effective but less expensive than galanthamine is pursuit worldwide. Widespread natural products like diterpenes from trachylobane class have been isolated in high yields from plants commonly present in several countries. Their ready availability and cosmopolite distribution makes them potential sources of novel drugs. In this context, we report herein the preparation and evaluation of trachyloban-19-oic acid (1) derivatives as acetylcholinesterase inhibitors.

\section{MATERIALS AND METHODS}

\section{GENERAL EXPERIMENTAL PROCEDURES}

Deuterated solvents were acquired from Sigma Aldrich (St. Louis, EUA) and Cambridge Isotope Laboratories (Tewksbury, USA), while analytical grade solvents and salts were obtained from Synth (Diadema, Brazil) or Vetec (Duque de Caxias, Brazil). Yeast extract was obtained from Biolog (Hayward, USA), sucrose from Synth and TLC plates from Silicycle (Québec, Canada); silica gel for column chromatograph was purchased from Merck (Darmstadt, Germany) (230-400 mesh). Nuclear magnetic resonance (NMR) spectra were determined on a Bruker Avance DRX $400 \mathrm{MHz}$ with tetramethylsilane (TMS) as internal standard in chloroform- $d\left(\mathrm{CDCl}_{3}\right)(\mathbf{1})$, pyridine- $d_{5}\left(\mathrm{C}_{5} \mathrm{D}_{5} \mathrm{~N}\right)(\mathbf{5})$ or dimethyl sulfoxide- $d_{6}\left(\mathrm{DMSO}-d_{6}\right)(\mathbf{6})$. Chemical shifts $(\delta)$ are given in parts per million (ppm) relative to TMS. Coupling constants $(J)$ are given in hertz (Hz). ESI-MS spectra were obtained with a Shimadzu LCMS-IT-TOF instrument. Infrared (IR) spectra were recorded on a Thermo Scientific Nicolet spectrometer operating in 4000 at $600 \mathrm{~cm}^{-1}$ region. For AChE inhibitory activity were used acetylcholinesterase from Electrophorus electricus, acetylthiocholine iodide and acid 5',5'-dithio-bis(2-nitrobenzoate) by Sigma Aldrich, and Tris/HCl by Invitrogen (Carlsbad, USA). The absorbance in assay for AChE inhibitory activity was measured at $405 \mathrm{~nm}$ on a Microplate reader Biotec ELX 800.

\section{MICROORGANISM SOURCE}

A strain of Mucor plumbeus was kindly donated by Tropical Foundation for Research and Technology André Tosello, Campinas, Brazil and stored in Potato Dextrose Agar (PDA) under refrigeration at Laboratory of Bioassays and Biotechnology, LaBB, UFMG (Belo Horizonte, Brazil). Prior to use, colonies were brought to room temperature.

TRACHYLOBAN-19-OIC ACID ISOLATION AND DERIVATIVES PREPARATION

Dried fruits of Xylopia sericea were extracted from hexane. During the extraction, a solid material precipitated and removed by filtration. This material was solubilized and recrystallized from methanol/ acetone (3:2). After 48 hours, a solid precipitated and was filtered off, dried and analyzed by ${ }^{1} \mathrm{H}$ and ${ }^{13} \mathrm{C}$ NMR spectroscopy and melting point, being characterized as trachyloban-19-oic acid (1, 1075 $\mathrm{mg}$ ). A minor component was obtained from recrystallization of the remaining hexane extract 
and identified as 15 $\beta$-hydroxy-trachyloban-19-oic acid (2, $88.5 \mathrm{mg})$ (Table I). Methyl trachyloban19-oate (3) was prepared from iodomethane $(62 \%$ yield) (Boeck et al. 2005). Compound 1 was subjected to reduction from $\mathrm{LiAlH}_{4}$ to furnish trachyloban-19-ol (4) (34\% yield). Compounds 2-4 were identified by ${ }^{1} \mathrm{H}$ and ${ }^{13} \mathrm{C}$ NMR spectroscopy and melting points and are in accordance with data reported in the literature (Takahashi et al. 2001).

\section{BIOTRANSFORMATION EXPERIMENT}

M. plumbeus was transferred to Petri dishes containing PDA and allowed to grow for 7 days at room temperature. After full growth, spores were harvested and used for liquid medium inoculation. Forty-eight flasks containing liquid medium were used for biotransformation experiment (Rocha et al. 2010). Liquid medium was prepared using sucrose $(20.0 \mathrm{~g} / \mathrm{L})$, yeast extract $(10.0 \mathrm{~g} / \mathrm{L}), \mathrm{NaNO}_{3}$ $(3.0 \mathrm{~g} / \mathrm{L}), \mathrm{KH}_{2} \mathrm{PO}_{4}(1.0 \mathrm{~g} / \mathrm{L}), \mathrm{MgSO}_{4} .7 \mathrm{H}_{2} \mathrm{O}(0.5$ $\mathrm{g} / \mathrm{L}), \mathrm{KCl}(0.5 \mathrm{~g} / \mathrm{L}), \mathrm{FeSO}_{4} .7 \mathrm{H}_{2} \mathrm{O}(0.01 \mathrm{~g} / \mathrm{L})$ in distilled water. Flasks containing culture medium were sterilized, inoculated with $M$. plumbeus spores suspension and the fungus was allowed to grow at room temperature. After $24 \mathrm{~h}$, a solution of trachyloban-19-oic acid (1) $(80 \mathrm{mg} / \mathrm{L}$ in ethyl acetate) was equally distributed into the flasks containing M. plumbeus biomass. Two flasks containing only the culture medium and $M$. plumbeus spores were kept as control. All flasks were kept under shaking by nine days. At the end of this period, mycelium was separated by gravity filtration using filter paper and the broth was partitioned four times with ethyl acetate (700 $\mathrm{mL}$ ). Organic layers were combined and dried with anhydrous sodium sulfate. The solvent was removed under vacuum to furnish the ethyl acetate extract $(978 \mathrm{mg})$. This extract was subjected to silica gel column chromatography using a gradient starting from hexane/acetone (85:15) and finishing with methanol $100 \%$ as eluent. Biotransformation products $5(5 \mathrm{mg})$ and $\mathbf{6}(25 \mathrm{mg})$ were isolated from fractions 18 (hexane/acetone 8:2) and 41 (acetone $100 \%$ ), respectively.

Trachyloban-19-O- $\beta$ - $D$-glucopyranosyl ester (6): white solid; m.p. $155-168{ }^{\circ} \mathrm{C}$; $[\alpha]^{20}{ }_{\mathrm{D}} 333.33$ (c 1 , methanol); IR (DMSO solution in ATR) $v_{\max } / \mathrm{cm}^{-1}$ 3394, 1657, 1022, 998; ${ }^{1} \mathrm{H}$ NMR (DMSO- $d, 400$ $\mathrm{MHz}$ ): Table I. ${ }^{13} \mathrm{C}$ NMR (DMSO- $d$, $100 \mathrm{MHz}$ ): Table I. HRMS (ESI): $m / z$ 487.2775 [M+Na] $]^{+}$ (calcd. for $\mathrm{C}_{26} \mathrm{H}_{40} \mathrm{O}_{7}[\mathrm{M}+\mathrm{Na}]^{+}$: 487.2672).

\section{ASSAY FOR ACHE INHIBITORY ACTIVITY}

AChE inhibitory activity was performed in 96 well microplates using a spectrophotometric method (Ellman et al. 1961, Teles and Takahashi 2013). There were used $25 \mu \mathrm{L}$ of acetylthiocholine iodide $(15 \mathrm{mM}), 125 \mu \mathrm{L}$ of Ellman's reagent (acid 5',5'-dithio-bis-(2-nitrobenzoate)) (3 mM) containing $0.1 \mathrm{M} \mathrm{NaCl}, 0.02 \mathrm{M} \mathrm{MgCl}_{2} \cdot 6 \mathrm{H}_{2} \mathrm{O}, 50$ $\mu \mathrm{L}$ Tris $/ \mathrm{HCl}(50 \mathrm{mM})$ at $\mathrm{pH} 8$ and $25 \mu \mathrm{L}$ of sample solution (prepared from DMSO $10 \mathrm{mg} / \mathrm{mL}$ ). Assay was carried out in quintuplicate and absorbance was measured at $405 \mathrm{~nm}$. Then, there were added $25 \mu \mathrm{L}$ of AChE solution $(0.222 \mathrm{U} / \mathrm{mL})$ containing $0.1 \%$ bovine serum albumin to the wells and absorbance was measured again. The percentage of inhibition was calculated by comparing rates of enzyme reaction of samples in relation to blank (DMSO) absorbance. Galantamine was used as a positive control. AChE percentage inhibition was calculated by using the equation:

Inhibition $(\%)=100-[($ RSsample $/$ RBcontrol)*100], where RSsample $=$ rate of sample extracts reaction and $\mathrm{RBcontrol}=$ rate of blank.

\section{RESULTS AND DISCUSSIONS}

Trachyloban-19-oic acid (1) showed moderate AChE inhibitory activity $(52.33 \pm 4.10 \%)$ (Table II) while its natural derivative 2 was significantly more active $(88.36 \pm 4.19 \%)$ which was an indicative that presence of a hydroxyl group in the molecule may 
be related to an improved $\mathrm{AChE}$ inhibition by this class of compounds. Conversion of carboxylic acid at C-19 of compound $\mathbf{1}$ into its alcohol derivative 4 caused a huge drop in activity $(30.99 \pm 4.38 \%)$ showing that a carboxyl group at C-19 has also positive effect over acetylcholinesterase inhibition. This was proven by preparing the ester derivative 3. Its activity was slight higher $(60.39 \pm 4.76 \%)$ than activity of trachyloban-19-oic acid (1) (Table II). Therefore, there were indicatives that presence of both a carboxyl group at C-19 in the skeleton is important for AChE inhibition.

Since biotransformations are a choice tool to insert hydroxyl groups in terpenes (Aleu et al. 1999, Barrero et al. 1999, Takahashi et al. 2014), compound 1 was fed to M. plumbeus aiming at obtaining hydroxylated trachylobane derivatives for biological screening as AChE inhibitors. After nine days of biotransformation, TLC profile of the resulting organic extract showed presence of biotransformation products, both of them more polar than starting material $\mathbf{1}$. The extract was subjected to silica gel column chromatography allowing isolation of products 5 and 6 (Figure 1). Their structures were determined by NMR experiments. Both products showed a double triplet at $\delta 0.57$ ppm, typical of $\mathrm{H}-12$ present in the cyclopropane ring of the starting material skeleton (Vasconselos et al. 2015). Structure elucidation of the products was accomplished after careful analysis of ${ }^{1} \mathrm{H}$ and ${ }^{13} \mathrm{C}$ NMR spectra and by correlations found in HSQC, COSY, NOESY and HMBC spectra (Table I). There were also used data from high resolution mass spectrum (HRMS) and infrared.
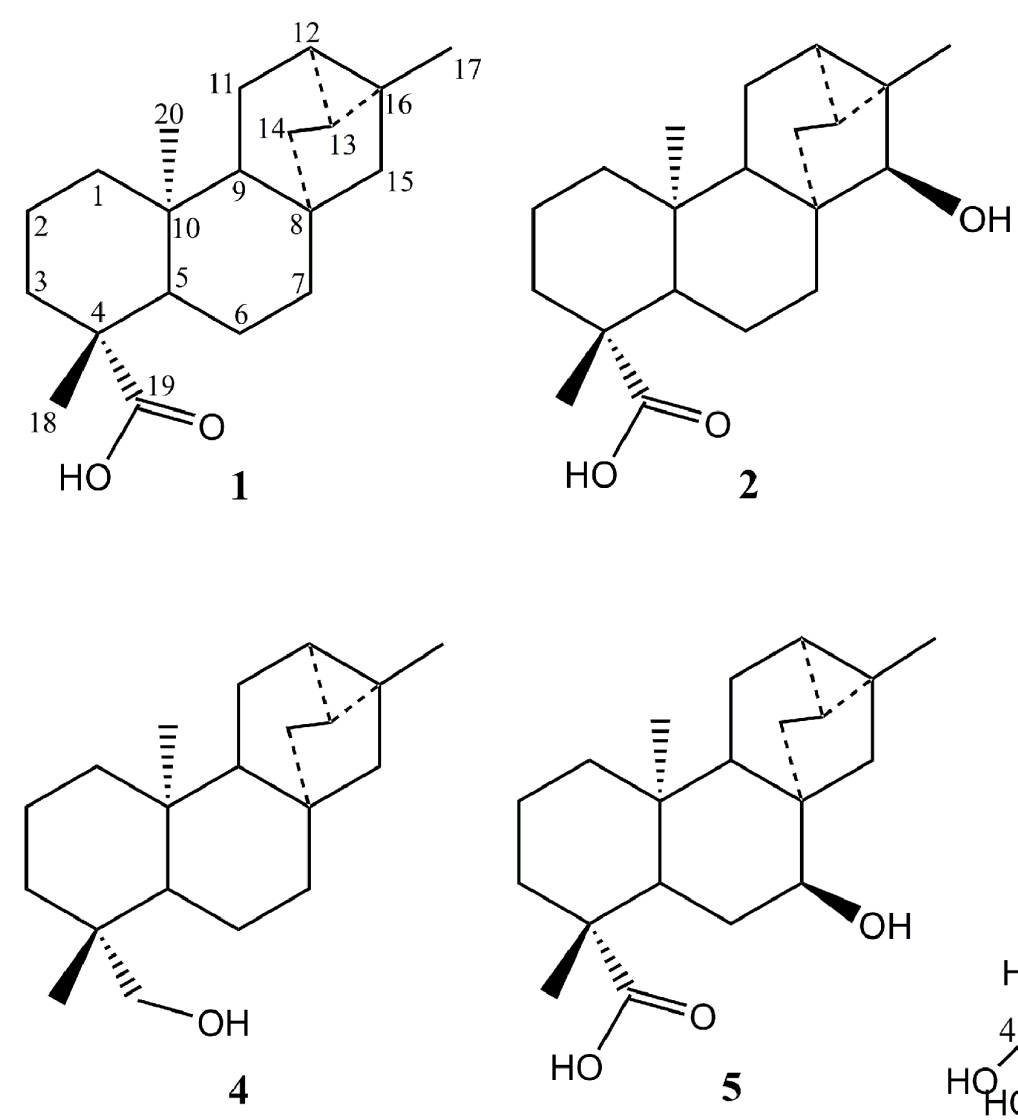
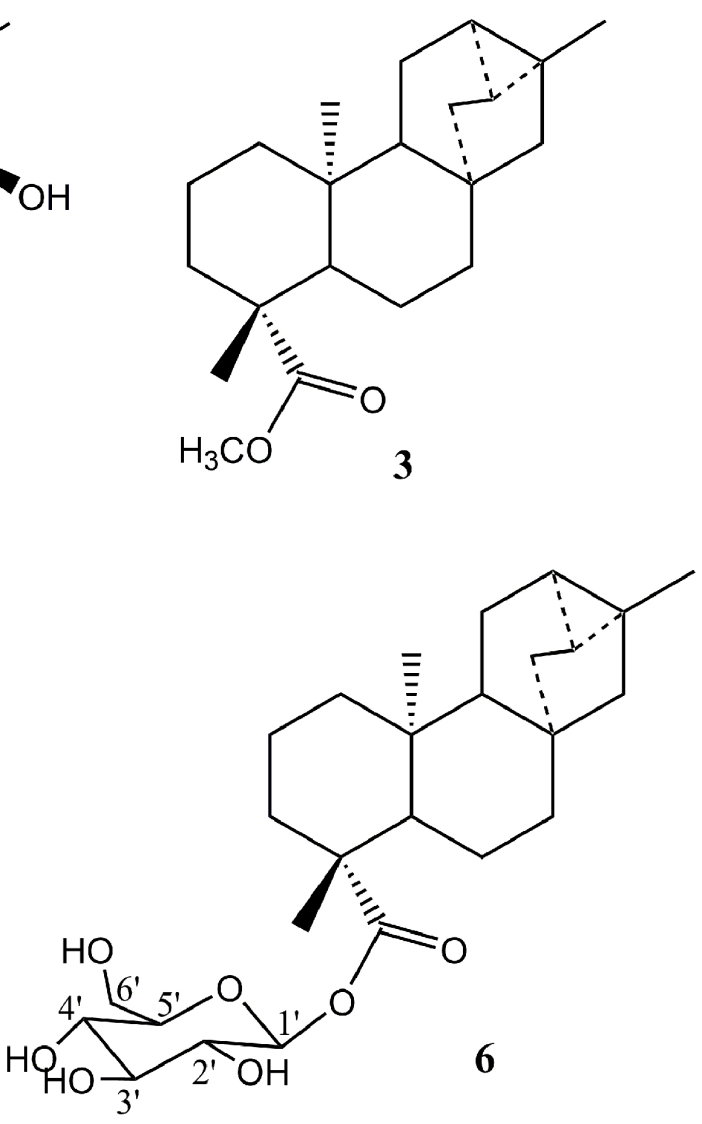

Figure 1 - Chemical structures of compounds 1-6. 


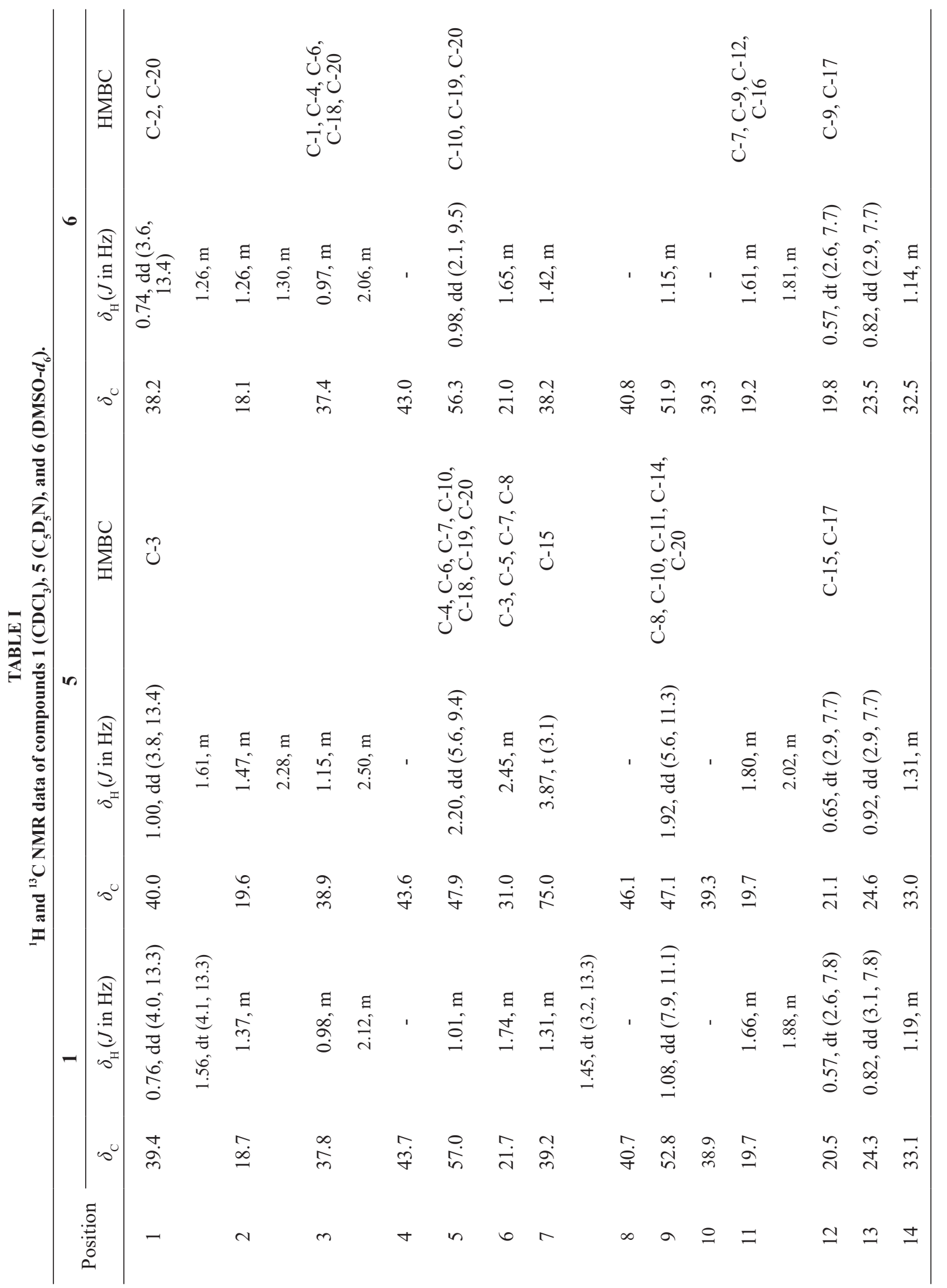




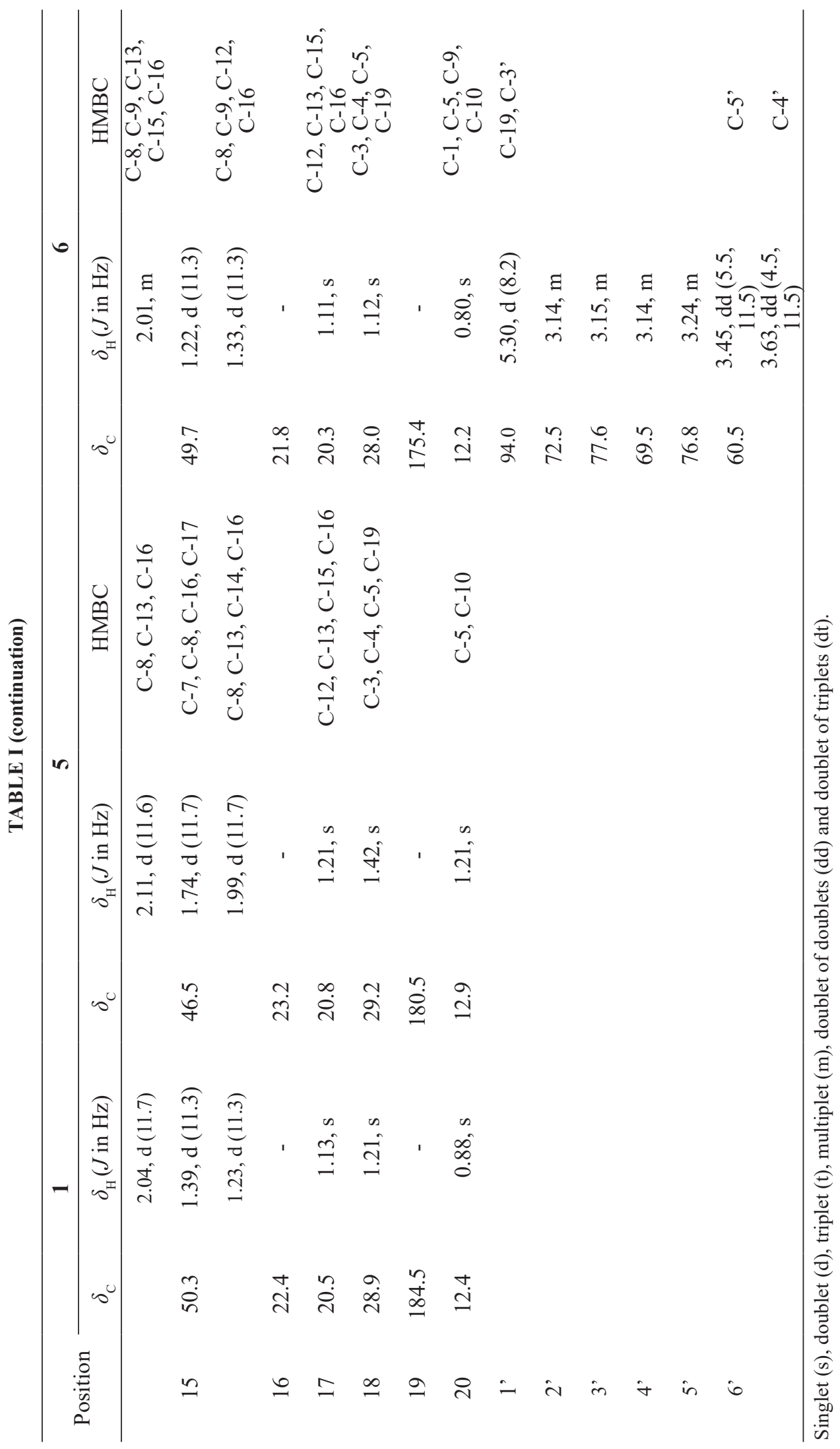


IDENTIFICATION OF COMPOUNDS OBTAINED BY BIOTRANSFORMATION

Product 5 was obtained as a white amorphous solid. ${ }^{13} \mathrm{C}$ NMR spectrum of $\mathbf{5}$ showed lack of a chemical shift assignable to C-7 (39.2 ppm in the starting material) while a new signal was detected at 75.0 ppm (carbinolic carbon), suggesting hydroxylation at C-7 position. $7 \alpha$-hydroxylated trachyloban19-oic acid (ciliaric acid) is a compound already described in the literature (Fraga 1994); however, ${ }^{13} \mathrm{C}$ NMR chemical shift reported for $\mathrm{C}-7$ of ciliaric acid did not match the value found for C-7 of product 5 (both spectra recorded in pyridine- $d_{5}$ ). Therefore, derivative 5 should possess $\beta$-stereochemistry at C-7. NOESY correlations found for $\mathbf{5}$ showed spatial proximity of hydrogen H-7 with H-6, H-14 and H-15. Since both hydrogen atoms at $\mathrm{C}-14$ are in the alpha face of the molecule, spatial correlation between $\mathrm{H}-7$ and $\mathrm{H}-14$ is only possible for an $\alpha$-hydrogen atom in C-7. Therefore, the hydroxyl group is indeed located in $\beta$ position. This correlation confirms the assignment of this product structure as 7 $\beta$-hydroxytrachyloban-19-oic acid (5), previously reported by Silva et al. (2002). Hydroxylation of non-activated methylene carbons is one of the most useful biotransformations (Faber 2011), usually performed by hydroxylases from Cytochrome P450 mono-oxygenases complex system (Montellano 2005).

Metabolite 6 was obtained as a white amorphous solid $(25 \mathrm{mg}) .{ }^{13} \mathrm{C}$ NMR spectrum revealed that all carbon signals of 1 were present, along which six new carbinolic carbon signals. Chemical shift of the carboxyl group at C-19 showed a significant alteration ( $\delta 184.5$ to $175.4 \mathrm{ppm})$, suggesting an esterification at $\mathrm{C}-19$ by a hexose in the structure of 6. HMBC correlations showed $J^{3}$ correlation of the anomeric hydrogen with $\mathrm{C}-19$. Multiplicity of H-1' $(J=8.2 \mathrm{~Hz})$ indicated that this hydrogen should be in axial position (Shimoda et al. 2006). Comparison of ${ }^{13} \mathrm{C}$ NMR data to the literature indicated that the hexose present in the structure of 6 should be a $\beta$ - $D$-glucopyranosyl group (Hu et al. 2012). Therefore, structure of $\mathbf{6}$ was determined as trachyloban-19-O- $\beta-D$-glucopyranosyl ester. This compound is reported herein by the first time to the best of our knowledge. Complete NMR assignment for compounds 1, 5 and $\mathbf{6}$ can be found in Table I.

In biological processes, glycosylation reactions catalyzed by glycosyltransferases are accomplished in three fundamental steps: activation, transfer and modification. Then, glycosyltransferase enzymes transfer a saccharide moiety from an activated nucleotide sugar molecule to a nucleophilic acceptor (Faber 2011, Huang et al. 2015). Glycosylation as a biocatalytic process is important because it can greatly influence the biological activity of natural products, increasing both chemical and biological stability of the compound (Overwin et al. 2015).

The activity for acetylcholinesterase inhibition of biotransformation products 5 and $\mathbf{6}$ was measured (Table II). As expected, compound $\mathbf{5}$ was very active $(51.95 \pm 1.93 \%)$, since this compound bears two groups important for activity, a carboxyl group at C-19 and also, a hydroxyl group, like compound 2. Glycosylation in C-19 was the most significant structural modification leading to the highest activity $(92.89 \pm 0.18 \%)$ among the tested compounds, a level of inhibition comparable to Galanthamine, the positive control used in the bioassay $(94.21 \pm 0.20)$.

AChE inhibition of trachyloban-19-oic acid (1) and biotransformation products 5 and $\mathbf{6}$ was analyzed in four concentrations, ranging from 10 to $0.625 \mathrm{mg} / \mathrm{mL}$ (Figure 2).

The original natural product (1) was the least active compound. Conversion of $\mathbf{1}$ into $\mathbf{5}$ by biotransformation significantly affected AChE inhibition, since 5, nevertheless as active as the precursor 1, was active up to the concentration of $1250 \mu \mathrm{g} / \mathrm{mL}$, although still less active than galantamine. On the other hand, glycosylated biotransformation product $\mathbf{6}$ was active up to 


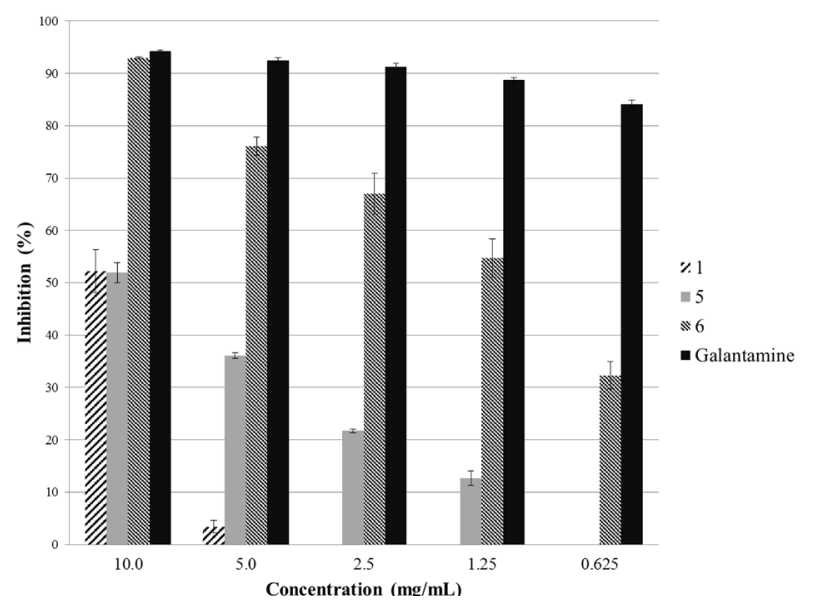

Figure 2 - AChE Inhibitory Activity of 1, 5, $\mathbf{6}$ and galantamine at the concentrations of $10.0,5.0,2.5,1.25$ and $0.625 \mathrm{mg} / \mathrm{mL}$

TABLE II

Percentage of AChE inhibition of diterpenes 1-6 (10 mg/mL).

\begin{tabular}{ccc}
\hline Compounds & AChE Inhibitory (\%) & Standard Deviation \\
\hline Galantamine & 94.21 & 0.20 \\
1 & 52.23 & 4.10 \\
2 & 88.36 & 4.19 \\
3 & 60.39 & 4.76 \\
4 & 30.99 & 4.38 \\
5 & 51.95 & 1.93 \\
6 & 92.89 & 0.18 \\
\hline
\end{tabular}

the concentration of $625 \mu \mathrm{g} / \mathrm{mL}$, being as active $(92.89 \%)$ as galanthamine $(94.21 \%)$ at the concentration of $10000 \mu \mathrm{g} / \mathrm{mL}$, but also active in lower concentrations. AChE inhibitory activity of biotransformation products $\mathbf{5}$ and $\mathbf{6}$ was dose dependent implying that these derivatives should possess selective action on acetylcholine inhibition.

In conclusion, biotransformation of the natural product trachyloban-19-oic acid showed to be a good tool to produce new activated compounds of trachylobane diterpenes class. Trachyloban-19-O- $\beta-$ $D$-glucopyranosyl ester (6), obtained as the major biotransformation product, was highly active for inhibition of AChE, an enzyme directly targeted in the treatment of Alzheimer's disease. Presence of the $19-O-(\beta-D$-glucopyranosyl) group in trachylobanoic acid skeleton increased acetylocholinesterase inhibitory activity, while starting material trachyloban- 19-oic acid (1) was moderately active. The report of AChE inhibitory activity for this class of compounds is very relevant since trachylobane diterpenes can be isolated in high amounts from nature (Hernández et al. 2012) being a straightforward source of starting material for industrial new drugs development. Therefore, drugs from this class arise as potential greener and cheaper alternatives for the development of anti-Alzheimer medicines to replace available medicines currently used in therapeutics.

\section{ACKNOWLEDGMENTS}

The authors are grateful to the Brazilian Funding Agency Conselho Nacional de Desenvolvimento Científico e Tecnológico (CNPq) and Fundação de Amparo à Pesquisa de Minas Gerais (FAPEMIG) for fellowships and financial support. To Tropical Foundation for Research and Technology André Tosello, Campinas, Brazil, for microorganism donation.

\section{REFERENCES}

ALEU J, HANSON JR, GALÁN RH AND COLLADO IG. 1999. Biotransformation of the fungistatic sesquiterpenoid patchoulol by Botrytis cinerea. J Nat Prod 62: 437-440.

ALVIN A, MILLER KI AND NEILAN BA. 2014. Exploring the potential of endophytes from medicinal plants as sources of antimycobacterial compounds. Microbiol Res 169: 483-495.

BARRERO AF, OLTRA JE, RASLAN DS AND SAÚDE DA. 1999. Microbial transformation of sesquiterpene lactones by the fungi Cunninghamella echinulata and Rhizopus oryzae. J Nat Prod 62: 726-729.

BAYDOUN E, ATIA-TUL-WAHAB, MEHMOOD $\mathrm{H}$, AHMAD MS, MALIK R, SMITH C AND CHOUDHARY MI. 2016. Microbial transformation of danazol with Cunninghamella blakesleeana and anti-cancer activity of danazol and its transformed products. Steroids 105: 121127.

BOECK P, SÁ MM, SOUZA BS, CERCENÁ R, ESCALANTE AM, ZACHINO SA, CECHINEL FILHO V AND YUNES RA. 2005. A simple Synthesis of Kaurenoic esters and other derivatives and evaluation of their antifungal activity. J Braz Chem Soc 16: 1360-1366.

CHEN LX, ZHAO Q, ZHANG M, LIANG YY, MA JH, ZHANG XH, DING LQ, ZHAO F AND QIU F. 
2015. Biotransformation of curcumenol by Mucor polymorphosporus. J Nat Prod 78: 674-680.

DONOVA MV AND EGOROVA OV. 2012. Microbial steroid transformations: current state and prospects. Appl Microbiol Biotechnol 94: 1423-1447.

ELLMAN GL, COURTNEY KD, ANDRES JRV AND FEATHERSTONE RM. 1961. A new and rapid colorimetric determination of acetylcholinesterase activity. Biochem Pharmacol 7: 88-90.

FABER K. 2011. Biotransformations in Organic Chemistry. A textbook. $6^{\text {th }}$ ed., Springer: Heidelberg, 405 p.

FRAGA BM. 1994. The trachylobane diterpenes. Phytochem Analysis 5: 49-56.

HERNÁNDEZ DM, DÍAZ-RUIZ G, RIVERO-CRUZ BE, BYE RA, AGUILAR MI AND RIVERO-CRUZ F. 2012. Ent-trachyloban-19-oic acid isolated from Iostephane heterophylla as a promising antibacterial agent against Streptococcus mutans biofilms. Fitoterapia 83: 527-531.

HOLLMANN F, ARENDS IWCE AND HOLTMANN D. 2011. Enzymatic reductions for the chemist. Green Chem 13: 2285-2313.

HU J, SHI X, DING W, CHEN J AND LI C. 2012. Phenylpropanoid glycosides from Conyza japonica. Chem Nat Compd 48: 782-784.

HUANG FC, HINKELMANN J AND SCHWAB W. 2015. Glucosylation of aroma chemicals and hydroxy fatty acids. J Biotechnol 216: 100-109.

LV X, XIN XL, DENG S, ZHANG BJ, HOU J, MA XC, WANG ZB AND KUANG HX. 2012. Biotransformation of osthole by Mucor spinosus. Process Biochem 47: 25422546.

MONTELLANO PRO. 2005. Cytochrome P450: Structure, Mechanism, and Biochemistry. $3^{\text {rd }}$ ed., Kluwer Academic/ Plenum Publishers: New York, 617 p.

NAJAF Z, MAHDAVI M, SAEEDI M, KARIMPOURRAZKENARI E, ASATOURI R, VAFADARNEJAD F, MOGHADAM FH, KHANAVI M, SHARIFZADEH M AND AKBARZADEH T. 2016. Novel tacrine-1,2,3triazole hybrids: In vitro, in vivo biological evaluation and docking study of cholinesterase inhibitors. Eur J Med Chem 125: 1200-1212.

NUNES FM, DOS SANTOS GF, SARAIVA NN, TRAPP MA, DE MATTOS MC, OLIVEIRA MCF AND RODRIGUES-FILHO E. 2013. New fungi for whole- cell biotransformation of carvone enantiomers. Novel p-menthane-2,8,9-triols production. Appl Catal A-Gen 468: 88-94.

OVERWIN H, WRAY V AND HOFER B. 2015. Biotransformation of phloretin by amylosucrase yields three novel dihydrochalcone glucosides. J Biotechnol 211: 103-106.

ROCHA AD, DOS SANTOS GC, FERNANDES NG, PFENNING LH, TAKAHASHI JA AND BOAVENTURA MAD. 2010. Hydroxylation at Carbon-2 of ent-16-oxo17-norkauran-19-oic acid by Fusarium proliferatum. J Nat Prod 73: 1431-1433.

SHIMODA K, KONDO Y, NISHIDA T, HAMADA $\mathrm{H}$, NAKAJIMA N AND HAMADA H. 2006. Biotransformation of thymol, carvacrol, and eugenol by cultured cells of Eucalyptus perriniana. Phytochemistry 67: 2256-2261.

SILVA EA, TAKAHASHI JA AND OLIVEIRA AB. 2002. An interesting backbone rearrangement and novel derivatives from the biotransformation of trachyloban-19-oic acid by Rhizopus stolonifer. J Braz Chem Soc 13: 101-105.

SILVA EO, FURTADO NAJC, ALEU J AND COLLADO IG. 2014. Non-terpenoid biotransformations by Mucor species. Phytochem Rev 14: 745-764.

TAKAHASHI JA, GOMES DC, LYRA FH, DOS SANTOS GF AND MARTINS LR. 2014. The remarkable structural diversity achieved in ent-kaurane diterpenes by fungal biotransformations. Molecules 19: 1856-1886.

TAKAHASHI JA, VIEIRA HS AND BOAVENTURA MAD. 2001. Mono and diterpenes from seeds of Xylopia sericea. Quím Nova 24: 616-618.

TELES APC AND TAKAHASHI JA. 2013. Paecilomide, a new acetylcholinesterase inhibitor from Paecilomyces lilacinus. Microbiol Res 168: 204-210.

VASCONSELOS DHP ET AL. 2015. Biotransformation of the diterpene ent-18,19-dihydroxytrachylobane by Rhizopus stolonifer. J Braz Chem Soc 26: 1043-1047.

XU F, LIAO K, LIU Y, ZHANG Z, GUO D, SU Z AND LIU B. 2016. Biotransformation of patchoulol by Cunninghamella echinulata var. elegans. Fitoterapia 109: 201-205.

YANG X, GE H, SONG Y, LI J AND CHEN G. 2015. Microbial transformation of 20(S)-protopanaxatriol by Mucor spinosus. Biotechnol Lett 37: 397-402. 